\title{
THE GUIDE TO ASSESSMENT OF RENOVATION AND MODERNIZATION PLANS ON WORN OUT TEXTURE FROM PERSPECTIVE OF SOCIAL STUDIES AND ITS IMPACT ON PHYSICAL FEATURES (CASE STUDY: WORN OUT TEXTURE OF ARDABIL CITY)
}

\author{
Hamid Lotfollahian \\ $\mathrm{PhD}$ student, Gazi University of Ankara \\ hamid19732002@yahoo.com
}

Solmaz Namadieslam

Faculty member at Sama Technical and Vocational College,

Sama technical and vocatinal training college, Islamic Azad University,Ardebil Branch,Ardebil,Iran s.namadieslam@yahoo.com

\begin{abstract}
Nowadays, it is essential and serious to conduct deep and efficient social studies and build thematic applied indices for designing the renovation and modernization plans of worn-out urban texture particularly empowering them, so that the implementation of any plan to rebuild the worn out texture will not lead to effective result without attention to its social studies. Modernization and reorganization of historical and valuable texture in Ardabil City promotes the quality of urban environment and life conditions and reconstructs the atmosphere of thought, reflection and interaction between human, society and the environment due to the hidden and enduring architectural values of some buildings, public spaces and also the other cultural and social values within it along with central and peripheral worn-out textures of city. According to social research assessment of worn out texture in Ardabil City, there has not been serious attention to social issues in these studies. The research findings indicate that there is a need for attention to social diversity, institutions, rules and behavior, and public participation in order to implement the urban planning in these textures.
\end{abstract}

Keywords: Worn out texture, renovation and modernization, social studies, physical features

\section{Introduction}

The renovation and modernization of worn out textures in Iran have been considered since it has been difficult to live in most of the central and middle textures of cities from physical, structural, environmental and social aspects, and the residential conditions in these textures have not been consistent with needs of current life; and there have been inefficient current functionality of these internal elements (i.e. human and activity) with each other and also with other relevant elements (in entire city). The outcome of this issue is seen in the form of textures with unacceptable and low-value social status in cities. The key features of these textures include their vulnerability to incidents such as earthquakes, lack of path and access grid, lack of proper access to public service, lack of open spaces, the inadequate sewage disposal, etc which totally introduce the unstable quality of urban life and unhealthy texture.

The importance of social factors and the need for conducting social studies and its effective links with other categories of urban development plan is obvious in urban studies, but the social research sector of numerous urban plans is practically stopped at the stage of status quo investigation and remained as the abstract studies separated from economic studies, transportation, municipal utilities and physical studies. However, the desirable and considered urban planning should study the interactions between variables and specific results of each study for other aspects of urban studies and 
topics. Furthermore, the stability and development of urban community is one of the important basic principles of sustainable development, and this is dependent on sustainable social development and the status and function of city in national and regional spaces because the access to sustainable development is provided only by social sustainable growth. Unfortunately, a majority of our urban plans are implemented based on urban information and a series of geometric accuracy and aesthetic edits and share tables and determination of per capita and finally drawing the map and present and future criteria of a city, and there is too few deep and profound studies on social issues.

Nowadays, it is essential and serious to provide renovation and modernization plans for worn out urban textures especially by conducting deep and efficient social studies on empowerment and building applied indices, so that the implementation of any plan to rebuild the worn out textures will not become successful without more attention to its social studies; and in other words, it will lead to loss of power and energy in the community. However, there has not been any logical and significant correlation between social studies and final projects provided by consultants according to description of service and projects for worn out textures, and this can lead to irreparable problems for city and its citizens.

In fact, the data should be generated in assessment of social impact of projects in order to measure the social local success in improving the lifestyle achieve the skills due to the implementation of plan as an approach to social studies on worn out texture. Furthermore, this data should be utilized to measure the improvement of existing institutions and their performance. It should be noted that we are seeking to collect the fundamental and necessary data, based on which we can evaluate and measure the project after implementation, in this article.

With an ancient history and religious, cultural, environmental, tourist, etc values, Ardabil city is among the cities where we cannot ignore the worn out central regions and valuable collections, and we should undoubtedly try to protect and promote those values.

\section{Importance and necessity}

The urban plans of Iran do not pay serious attention to social dimensions and this reduces the success of these plans. Therefore, it is necessary to evaluate the social dimensions of studies on renovation and modernization plans in order to identify the weaknesses of studies on worn out textures in the field of social aspect and prevent them in future plans.

\section{Literature review}

The city is like a container including the citizens with their relationships, needs, demands and interest. The citizenship rights, a sense of safety and security, sense of self-existence and living with others, etc all creates a space called the civil court in city. A direct relationship is established between urban body and soul in such this court [1].

Due to the severe problems in urban historical textures such as environmental pollution, traffic problems, unsafe roads and loss of spatial quality in texture, the increased psychological pressure, etc in recent decades, the scientific communities and officials have made policies to take steps towards renovating and modernizing these areas, for instance, drawing and providing the guidelines for spatial continuity in these textures as well as expanding the pedestrian areas in the forms of alley, market, small markets, a path in square, park or space of complexes as well as creating a place for renovating these areas. The significant impact of these textures on issues such as demographic and social, economic, and infrastructural issues and urban service is among the most important issues which require attention to worn out textures. A numerous worn out textures are extremely vulnerable to natural disasters and faced with physical deconstruction due to the use of old and low cost construction materials in terms of physical strength. These textures become worn out and lose their urban functions over time [2].

The central urban textures, where are mostly built without previous plans, have irregular structures and they can be often accessed by walking, so that most of their paths are dead-end with widths less than six meters and low permeability coefficient. The service, infrastructures, and open, green and vertical spaces have serious deficiencies [3].

On the other hand, these textures have fundamental deficiencies due to the age and in most of the cases the worn out structures and lack of essential facilities and service for today's urban life in 
fulfilling their citizens' needs. Therefore, there is a need for purposive intervention, maintaining the identity of central texture, and its evolution and dynamics in order to maintain the urban structure. Therefore, the urban issues cannot be solved unless the citizens' needs, desires and attitudes are identified in contemporary world; and the issues cannot be identified unless the research is conducted. The social research can be used for policies of planning social, housing, education, health and so on. The awareness of public needs and problems and their attitudes towards their roles in solving the urban problems has made an appropriate basis for logical and proper communication between service institutions and citizens. Furthermore, the citizens' trust in urban renovation plan can affect the provision of economic resources, reduced service costs, increased social cohesion, reduced damages and stresses of urban life and citizens' satisfaction [4].

\section{Research objectives}

1- Collection of data from area in order to provide monitoring and evaluation of economic and social impact on this area;

2- Identification of existing social issues such as housing, rights of property or lease of land, infrastructural issues, and social service;

3- Identification of needs and priorities and existing social capacities;

4- Identification of smaller projects to improve the capacity of local institutions;

5- Providing a plan for participation of stakeholders in project implementation;

6- Establishment of social evaluation and monitoring approach to social studies on worn out area;

7- Providing strategies to solve existing shortcomings in national urban planning system in relation to social issues;

8- Providing strategies to strengthen the impact of social factors on planning for worn out textures;

9- Developing the social vision in planning for worn out textures;

10- Offering suggestions for optimum use of social factors in planning for worn out textures;

11- Achieving a favorable social development in cities

\section{Research questions}

- Do the social studies have rightful place in planning for worn out textures in our country?

- Is it possible to strengthen the positive effects of social factors on planning for worn out textures by some strategies?

- Does the current study on social contexts of worn out textures solve the problems of these textures?

\section{Research hypotheses}

- It seems that the needs, capacities and socio-cultural and physical priorities of worn out textures are not clearly studied in accordance with conditions of these textures.

- It seems that the social studies do not have proper position in planning for worn out textures in our country.

- It seems that the positive effects of social factors can be strengthened on planning for worn out textures by some strategies.

\section{Research methodology}

Three data collection methods have been taken into account in order to achieve the aforementioned objectives:

- Review of books, papers, document, and reports of the Management and Planning Organization, Municipality, Governorate, Department of Social Welfare, University, Education system and ...

- Quantitative methods: The questionnaire has been as the main data collection tool in this section.

- Qualitative studies which have focused on techniques such as in-depth interview, concentrated group sessions, observation and survey of public facilities.

\section{Theoretical principles of research}


Plato, Aristotle and al-Farabi were those who talked about ideal city and measures based on solving the city residents' physical and spiritual needs by cooperation and consultation with citizens. Those measures were like the practices which are now called the urban renovation and modernization. These measures include: Integration of old and new projects; quick and easy access to different regions of city; providing easy access to life necessities such as food and clothing; organizing the trade and communication; appropriate location and proportionality of public spaces in city; organizing the construction of urban structures, and providing the affordable housing for low-income residents, etc. [5].

Nigel Thrift refers to five basic concepts in class analysis: Class structure, formation, struggle, capacity and awareness. He claims that the role of geography has not taken into account in class analysis. For instance, Wallerstein et al have made class analysis at the global level. Class analysis of class structures is also a common way, and numerous class national geography and class analyses at the regional level [6].

Doreen Massey has paid more attention to the role of reproduction relations particularly gender relations in class structure in his book entitled "Spatial divisions of Labor". Furthermore, Massey believes that the social hierarchies have a spatial form, and there is a clear correlation between social and spatial differentiation [7].

There is a complex interaction between different areas of life, social reproduction and class relations. Urban space is related to reproduction of capitalist class in different ways. Capitalism is a tool for delaying the crises of increased capitalist accumulation in a human-made environment. The residential segregation leads to the further isolation of classes and their various branches and creates an environment which fuels the working class subculture and structures them alongside the boundaries of ethnicity and skill level [8].

D.T. Herbert believes that the distribution of deviant behavior has a static correlation with certain characteristics of spatial and social environment, so that the residential area can be a valid index for different social groups. It is true that some forms of deviance have dispersed spatial forms, but the deviance is typically concentrated in certain parts of city. The spatial distribution of deviance cannot be predicted only from the deviant social groups and spatial arrangement of these groups, but also the spatial characteristics of environment play roles in understanding the geographical distribution of deviant behavior [9].

in comparative pathology ecology discussion in city, Shakuie has considered a certain and reliable relationship between distribution of diseases, and triple physical, mental and social factors with air and noise pollution, pollution density, and people concentration in the room and residential unit, economic status, poverty, unemployment and illiteracy, non-standard and unsafe housing units. He has considered the knowledge about correlation between physical conditions of environment as the major task of studies on comparative ecology [10].

\section{Introduction of studied area}

The worn out textures of Ardabil City are limited in five separate regions. These areas have wide differences with each other in terms of spatial and temporal characteristics of creation and physical, social, economic, etc features. Figure 1 shows the location of all five sectors in the whole city. 


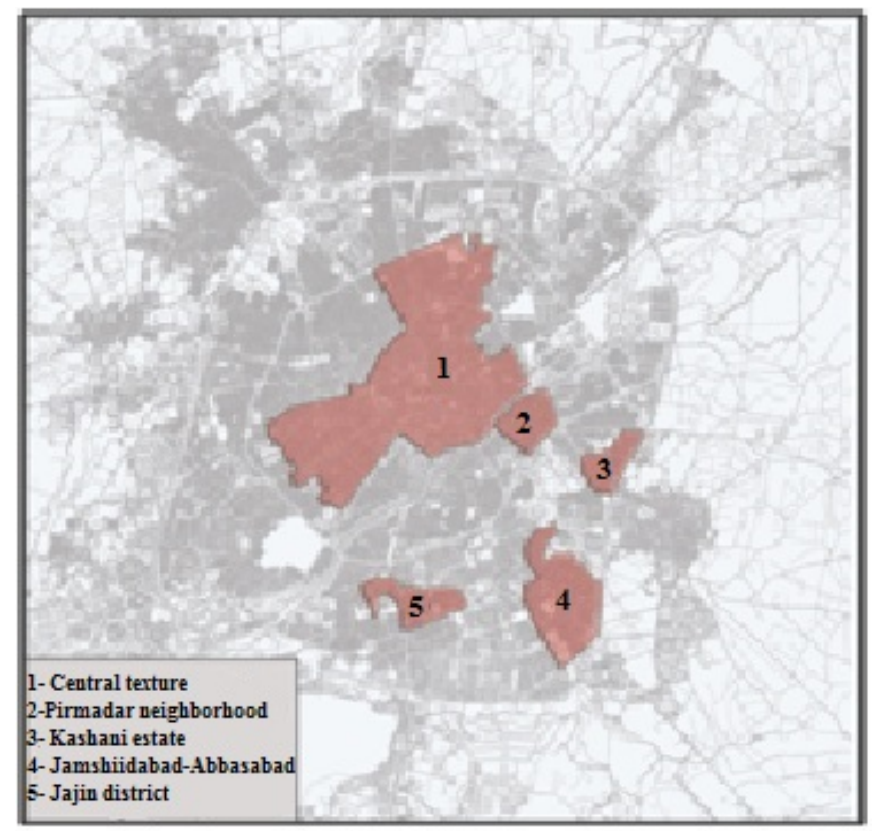

Figure 1- Location of worn out textures in Ardabil City

\subsection{Introduction of central and historical areas}

This region with an area of 371 hectares includes the highest level of worn out texture and consists of both historical and central textures. The first region is the geometrical and spatial city center and is in fact the primary core of its formation and almost covers the entire range in zero ring (Enghelab, Sheikh Safi, Pasdaran, Jomhuri Eslami and Khoramshahr streets). The existence of Ardabil market (Bazaar) and historical sites including Tabar, Ali-Qapu, Ochdokan and ... and also the existence of elements such as Sheikh Safi al-Din Khānegāh and Shrine Ensemble and Jome Mosque hill inside it are the main features of this space.

The second region of central area is a semi-organic texture formed around the primary core; and the worn out texture is limited as a sector towards the north and south of this core. This texture is resulted from the urban growth contemporary era and is the outcome of transition from organic texture to regular and semi-regular urban texture (Figure 2).

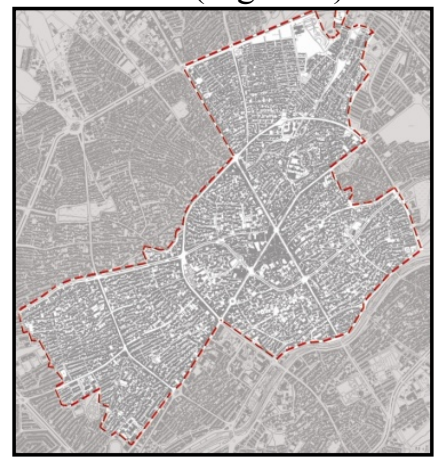

Figure 2: Central and the historical area of old texture

\subsection{Pirmadar neighborhood}

This region is located at the southern edge of Balighu River in the southeast of central texture and has an area of 29 hectares. Pirmadar neighborhood is also an ancient neighborhood of city and is among the first development of historical texture in contemporary era. This area is limited to Abu Taleb Street in the east, Shohada Highway in the south, Shahid Purrahimi Street in the west (Figure $3)$. 


\subsection{Kashani estate}

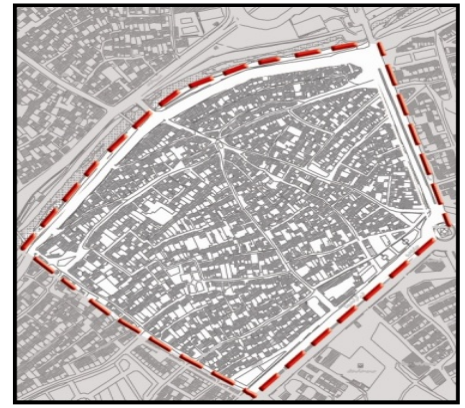

Figure 3- Pirmadar District

This region with an area of 23 hectares is among the suburban areas and located in northern margin of second ring road (Basij highway) in the east Ardabil. This area is ended in Razi St. from north, Niar Road from south, and 35-meter Fajr St. from the west. The establishment of non-durable buildings and its irregular and non-standard grid are among the features of this area (Figure 4).

\subsection{Jamshidabad and Abbasabad districts}

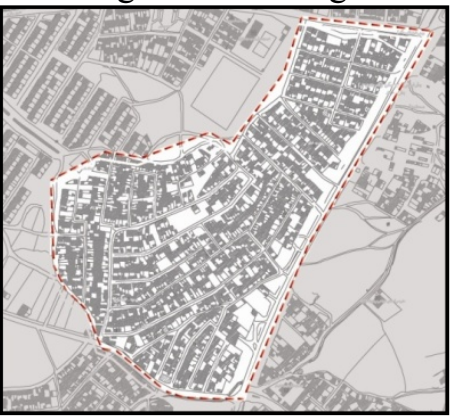

Figure 4- Kashani estate

This region is located at the southern entrance of city (Khalkhal road) and in the both sides of Besat Street and covers a part of both Jamshidabad and Abbasabad neighborhoods. This region has irregular textures with use of poor and non-durable materials in building, and the western side of street has better situation than the eastern. The overall area of this region is 80 hectares (Figure 5).

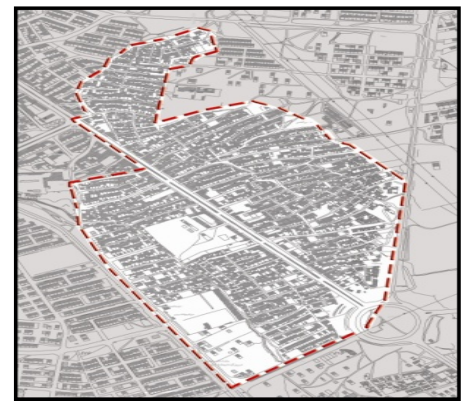

Figure 5- Jamshidabad and Abbasabad neighborhoods

\subsection{Jajin neighborhood}

This region with an area of 33 hectares is located in the south of city and is among the most expensive lands in Ardabil city. The general features of texture are as follows:

- Very irregular texture

- Inadequate and non-standard access

- Irregular establishment of parts in all directions

- Establishment of low and non-durable buildings in the area (Figure 6). 


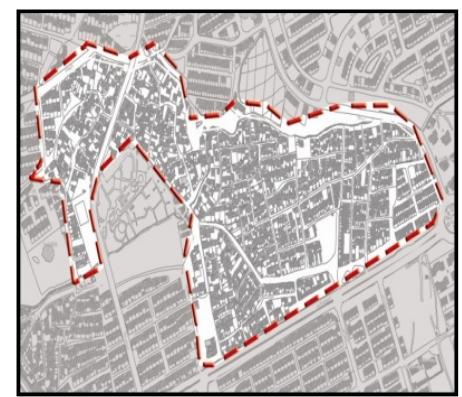

Figure 6- Jajin neighborhood

\section{Research results}

\subsection{Family stay in plaque}

The history of residence in the neighborhood is an index which indicates the neighborhood social status in terms of ethnic and cultural change. The residence history is the most representative of residents' homogeneous social composition and their belonging to residence in that neighborhood. The long stay in the neighborhood will remain memories in the minds and it is difficult to leave them, and this can strengthen belonging to the neighborhood. In neighborhoods with low history of residence, the social texture is heterogeneous, ethnic diversity is high and possibly the attachment to environment is low, and leaving is easy. All these factors make a neighborhood as a container which constantly becomes full and empty and it is not easy to plan for it.

\subsubsection{Areas $(1,2,4)$ : Worn out texture without historical heritage}

Based on the conducted field studies in studies area, 92 questionnaires are distributed and $42.7 \%$ of residents have had over 20 years or from 10 to 20 years of residence which is a high percentage and indicates belonging to the neighborhood. 4.16 percent have had less than 6 years and about 3-6 years of residence. $11.45 \%$ from 6 to 10 years, $9.37 \%$ from 1 to 3 years, and $26.04 \%$ have had more than 10 years of residence. Diagram (1) shows the history of residence in this area.

Diagram 1: Investigation of householder' length of stay in studied areas $(1,2,4)$

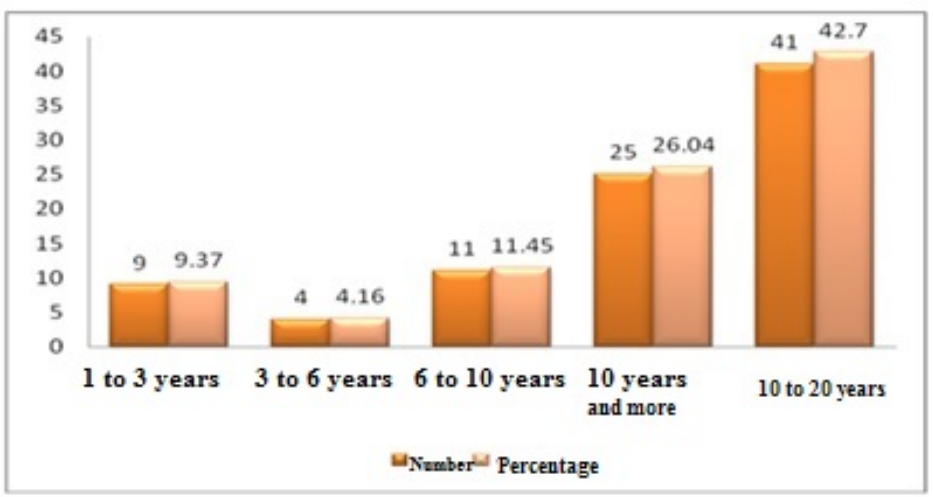

\subsubsection{Area 3: Worn out texture with historical heritage}

52 questionnaires are distributed in studied area and $59.61 \%$ of residents have had a living history of more than 20 years and from 10 to 20 years of residence as the high percentage indicating belonging to neighborhood. 1.9 percent of them have had a history of less than 6 years and about 3-6 years. $9.6 \%$ from 6 to 10 years, 9.6 percent from $1-3$ years, and 12.38 percent more than 10 years. Diagram 2 shows the householder' length of stay in area.

Diagram 2: Investigation of householder' length of stay in studied area 


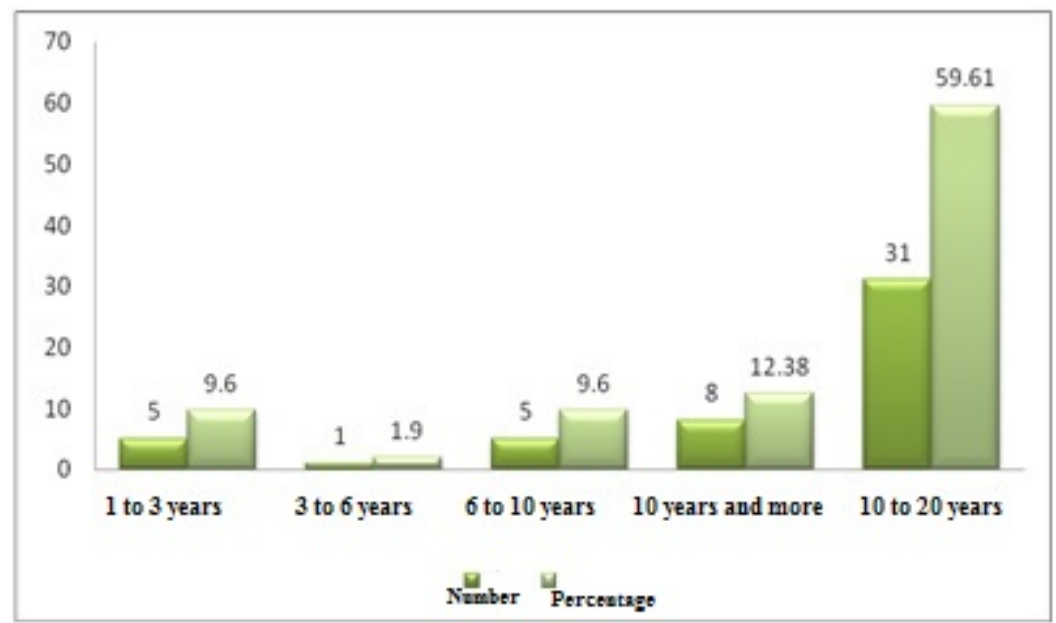

\subsection{Desire to modernization and renovation}

\subsubsection{Areas $(1,2,4)$ : Worn out texture without historical heritage}

Among 92 respondents to questionnaires in studies area, if most of the respondents $(58 \%)$ or 60.41 percent are householders, they will be willing to do renovation and modernization, but 34 ones or 35.41 percent will have no desire to modernization (Diagram 3).

Diagram 3: Investigation of householder' willingness to modernization in studied area $(1,2,4)$

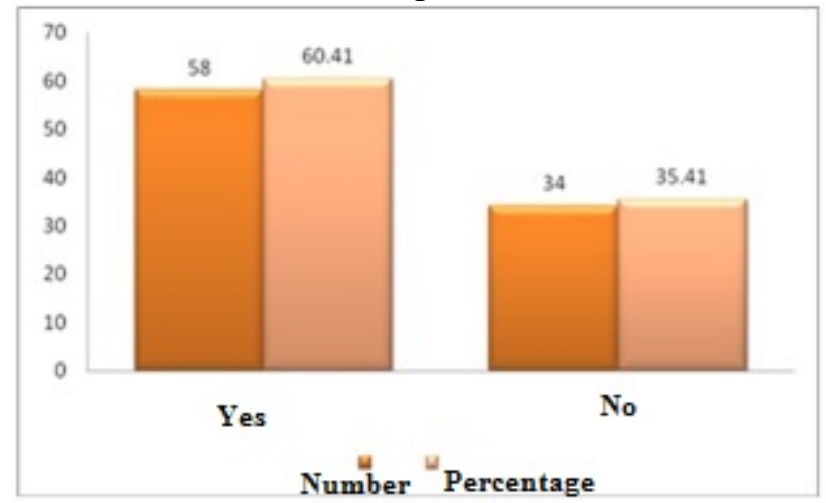

\subsubsection{Area 3: Worn out texture with historical heritage}

Among 46 respondents to questionnaires in studies area, if most of the respondents (29 ones) or 55.76 percent are householders, they will be willing to modernization, but 17 ones or 32.69 percent will have no willing to modernization (Diagram 4).

Diagram 4: Investigation of householders' willingness to modernization in studied area 3

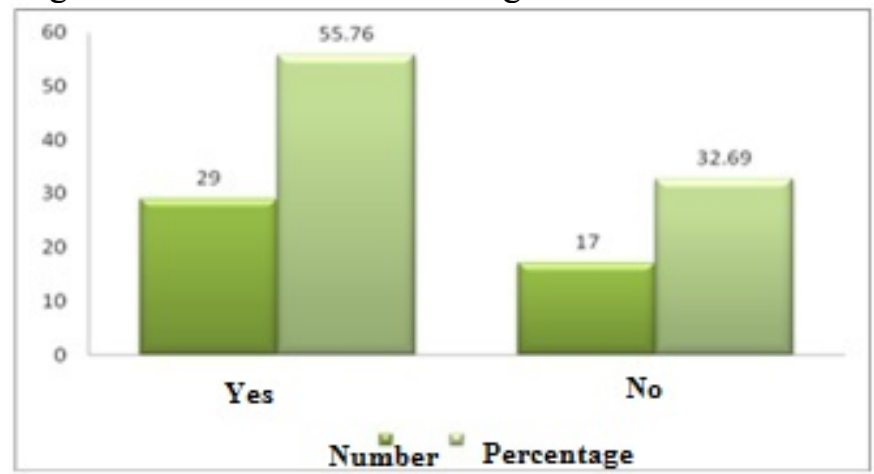

\subsection{Measures to modernization}

\subsubsection{Areas $(1,2,4)$ : Worn out texture without historical heritage}

Among 67 respondents to questionnaires in studied area, if most of the respondents ( 29 ones, or $30.2 \%$ ) are householders, they will be willing to build their own residential units according to plan in the case of receiving banking loans. While 5 respondents or $5.2 \%$ are willing to give their units as the contribution in the case that the construction costs are paid by an investor. 2 respondents of $2.08 \%$ 
are willing to give their units as the contribution through holding the local cooperatives and receive the equivalent figure after renovation. 13 ones or 13.54 are willing to sell their units and leave the area, and 16 ones or $16.66 \%$ are not willing to cooperate or sell the units (Diagram 5).

Diagram 5: Investigation of measures for modernization in studied area $(1,2,4)$

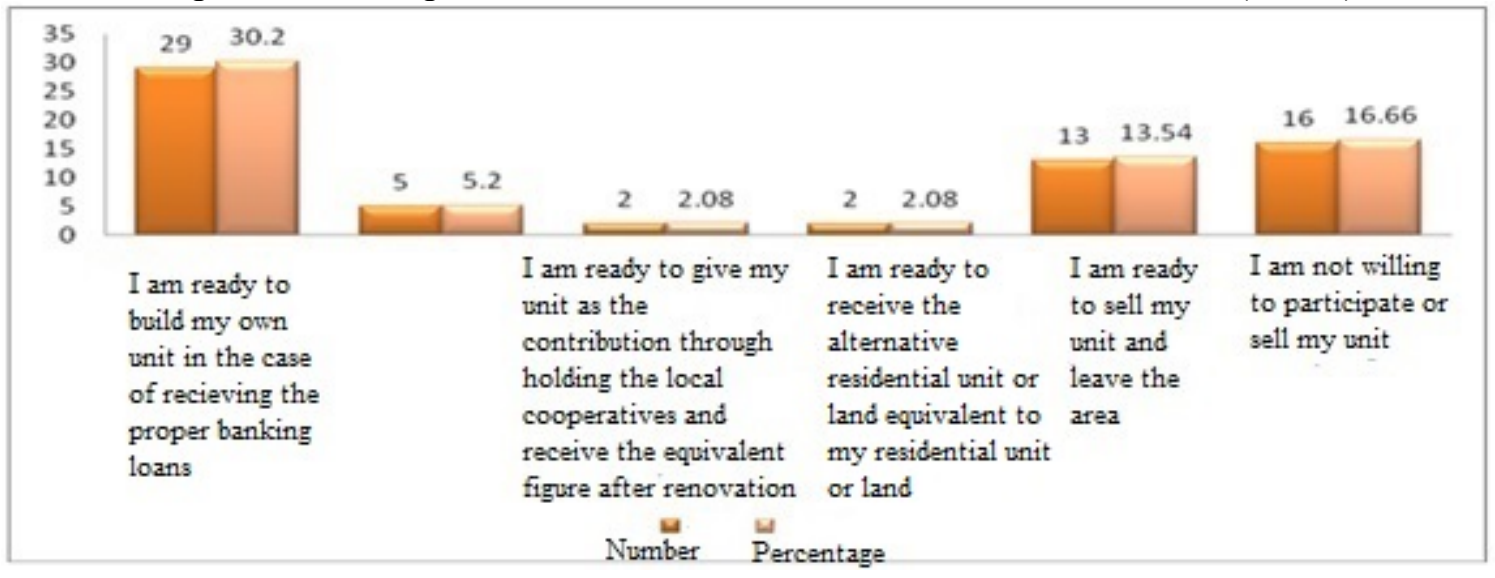

\subsubsection{Area 3: Worn out texture with historical heritage}

Among 29 respondents to questionnaires in studied area, if most of the respondents (16 ones, or $3076 \%$ ) are householders, they will be willing to build their own residential units according to plan in the case of receiving banking loans. While 1 respondent or $1.92 \%$ is willing to give his unit as the contribution in the case that the construction costs are paid by an investor. 1 respondent of $1.98 \%$ is willing to give his unit as the contribution through holding the local cooperatives and receive the equivalent figure after renovation. 5 ones or 9.61 are willing to receive the alternative residential units or lands equivalent to their residential units or lands. 2 ones or 3.84 are willing to sell their units and leave the area, and 4 ones or $7.69 \%$ are not willing to cooperate or sell the units (Diagram 6).

Diagram 6: Investigation of measures for modernization in studied area 3

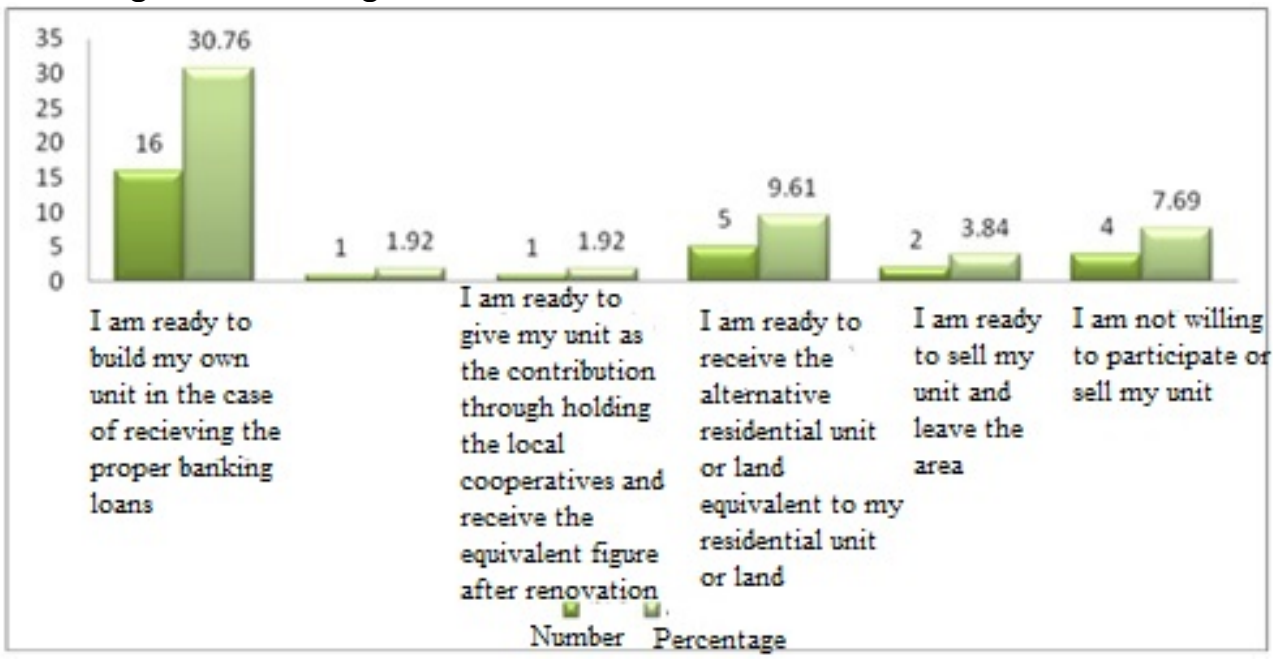

\subsection{Utilization of loan for renovation}

\subsubsection{Areas $(1,2,4)$ : Worn out texture without historical heritage}

Among 96 respondents in area, 28 respondents or $29.16 \%$ used the loans of banks or interestfree funds to renovate, build or purchase their houses, and 68 respondents or $69.79 \%$ never used the loans (Diagram 7).

Diagram 7: Use of loans to renovate in studied areas $(1,2,4)$ 


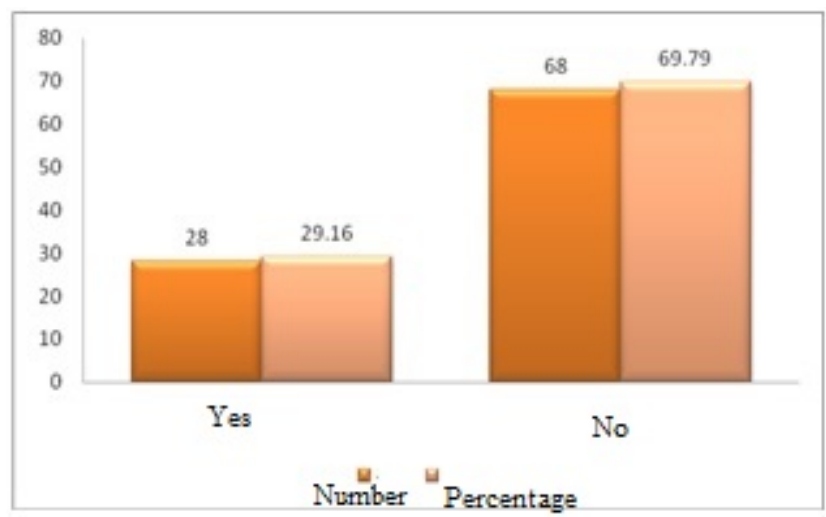

\subsubsection{Area 3: Worn out texture with historical heritage}

Among 45 respondents in area, 28 respondents or $53.84 \%$ used the loans of banks or interestfree funds to renovate, build or purchase their houses, and 17 respondents or $32.69 \%$ never used the loans (Diagram 8).

Diagram 8: Use of loans to renovate in studied area 3

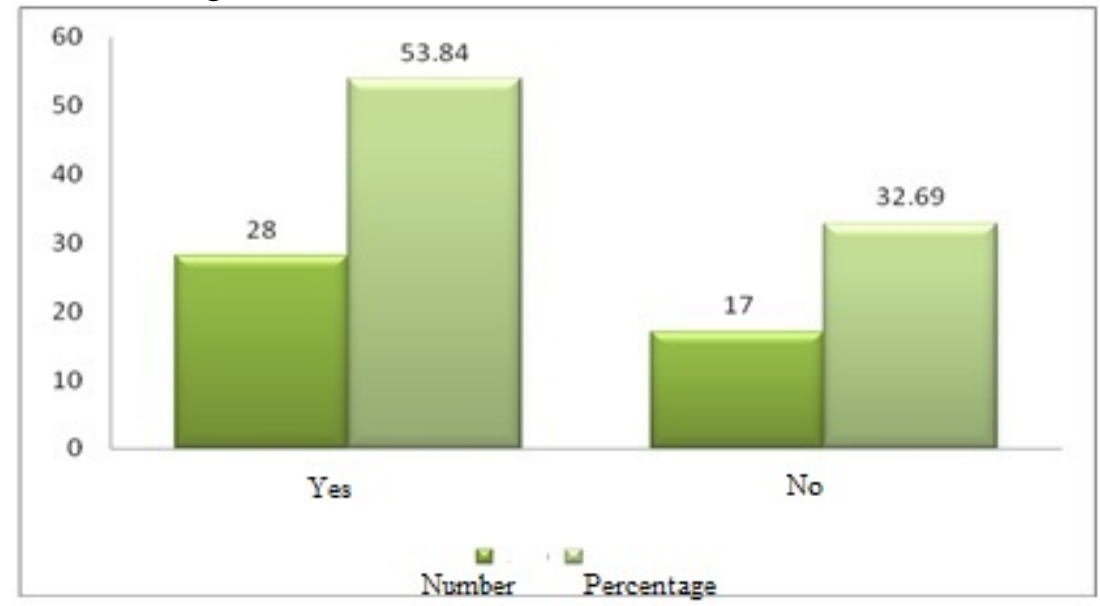

\section{Conclusion and offering the suggested strategies}

With regard to the participatory capacities, low levels of household income, poor urban infrastructures and service, improper physical condition of buildings, etc, the following strategies are offered to empower the inhabitants of such these settlements:

- Making the infrastructure for public participation in City Council;

- Drawing the modernization and rehabilitation projects for worn out textures by public participation

- Creating the perfect support to get banking facilities by revising the current assignment of loans;

- Reviewing all laws and regulations limiting the low-income people's access to official credit and loans;

- Solving the legal gaps in cooperation between the decision making entities in renovation of worn out textures particularly the Cultural Heritage Organization, the construction and renovation organization, and local management entity (council and municipality) as the most effective organizations involving in renovating and modernizing the urban worn out textures;

- Creating the deputy for organizing urban worn out textures in cities with this issue in a way that other local governmental bodies are obliged to cooperate and coordinate with it;

- Giving the responsibility of preparation and adoption of renovation plans for worn out textures to local urban management in order to make the process of plan preparation and adoption participative;

- Special help to create communal spaces (cultural, leisure and sports) in existing settlements;

- Use of sports groups, religious organizations, and female associations to organize public participation; 
- Increasing the citizens' awareness of worn out texture modernization and renovation issues and taking efforts to create awareness and sensitization through training by local institutions such as local Basij and council;

- Taking efforts to establish mutual trust between citizens and municipal administration so that the citizens can be a starting point for empowering residents in such these settlements.

\section{REFERENCES}

1. Danaeinia, Ahmad (2006) Neighborhood architectural structure in desert textures of Iran; proceedings of Regional Conference on desert architecture, Islamic Azad University of Ardestan.

2. Habibi, Kiomars; Pourahmad, Ahmad; and Meshkini, Abolfazl (2007), Modernization and renovation of urban old textures, Tehran, first edition.

3. Kalantari, Khalil (2008) Data processing and analysis in socio-economic research, Third Edition, Tehran: Farhange Saba.

4. Daneshpour, Seyed Abdolhadi; and Hadian, Akram (2009) The study on the role of citizen participation in implementation of renovation projects for worn out urban textures; Quarterly of Urban Management Research, First year, No. 2.

5. Habibi, Seyed Mohsen; Maghsoudi, Maliheh. (2002) Urban restoration, Tehran University Press, Tehran.

6. Thrift, Nigel, "Flies \& Germs: Geography of Knowledge" in Gregory, Derek \& John Urry (eds), Social Relatial and Spatial Structure,p.13

7. New Directions in Space “ in Gregory, Derek \& John Urry (eds ), Social Relations and Spatial Structure, p.146.

8. Pratt, Geraldire, "Reproduction, Class and the Spatial Structure of the City" in Richard, Peet \& Nigel Thrift ( deds), New Models in Geography,Vol.2,pp.84-101.

9. Herbert, D.T, "Social Deviance in the City" in Herbert, D.T. and R.J.Johnston ( eds), Spatial Perspectives on Problems and Policies,PP. 89-123.

10. Shakuie, Hossein, Urban social geography: Social ecology of city, pp. 99-116. 